\title{
ANÁLISE DE CRESCIMENTO DE DIFERENTES GENÓTIPOS DE CITROS CULTIVADOS SOB DÉFICIT HÍDRICO ${ }^{1}$
}

\author{
CLOVIS PEREIRA PEIXOTO²; ELAINE COSTA CERQUEIRA;3; WALTER DOS SANTOS SOARES FILHO ${ }^{4}$; \\ MANOEL TEIXEIRA DE CASTRO NETO ${ }^{4}$; CARLOS ALBERTO DA SILVA LEDO ${ }^{4}$; FÁBIO SANTOS MATOS; \\ JUTAIR GARCIA DE OLIVEIRA ${ }^{5}$
}

\begin{abstract}
RESUMO - Visando à identificação de genótipos de citros melhor adaptados ao ecossistema de Tabuleiros Costeiros, com potencial de uso como porta-enxertos, avaliou-se seu desempenho em relação à tolerância à seca, considerando a análise de crescimento das plantas. O trabalho foi conduzido em casa de vegetação da Embrapa Mandioca e Fruticultura Tropical, em Cruz das Almas - BA. Foram avaliados seis genótipos: limoeiros ‘Cravo' e ‘Volkameriano', laranjeira ‘Azeda' e os híbridos trifoliados HTR - 051, TSK õ CTTR - 002 e TSK õ CTTR 017, estes últimos obtidos pelo Programa de Melhoramento Genético de Citros da Embrapa Mandioca e Fruticultura Tropical. Plantas obtidas de sementes (pés-francos ou seedlings) foram cultivadas em substrato Plantmax ${ }^{\hat{a}}$, irrigando-as até que apresentassem dois ou mais pares de folhas verdadeiras, quando foram transplantadas para recipientes com o mesmo substrato devidamente adubado, mantendo-se o suplemento hídrico até o início das avaliações. O delineamento experimental foi o inteiramente casualizado, em esquema fatorial 6 õ 7 , sendo seis genótipos e sete tempos de avaliação. As avaliações foram realizadas sob irrigação, déficit hídrico e re-irrigação, considerando-se o acúmulo de matéria seca total (MS) e a área foliar da planta (AF) como base para a determinação dos seguintes índices fisiológicos: razão de área foliar (RAF), taxa assimilatória líquida (TAL) e taxa de crescimento relativo (TCR). Nas condições do experimento, o híbrido HTR - 051 apresentou menor sensibilidade ao déficit hídrico, o que o qualifica como porta-enxerto promissor para ambientes sujeitos a estiagem prolongada.
\end{abstract}

Termos para indexação: Tabuleiros Costeiros, híbridos, Citrus spp., Poncirus trifoliata.

\section{GROWTH ANALYSIS OF DIFFERENT CITRUS GENOTYPES CULTIVATED UNDER WATER DEFICIT}

\begin{abstract}
Aiming the identification of citrus varieties better adapted to Coastal Table Lands, considering their potential use as rootstocks, the performance of different genotypes for drought tolerance was evaluated, considering their physiological indices related to the growth analyses. The study was carried out in a greenhouse condition of the Embrapa Cassava \& Tropical Fruits. Six genotypes were studied: Rangpur lime, Volkamer lemon, Sour orange, and the hybrids HTR - 051, TSK õ CTTR - 002 and TSK õ CTTR - 017, all from the Citrus Breeding Program of the Embrapa Cassava \& Tropical Fruits. Seedlings were grown in Plantmax ${ }^{\hat{a}}$ growing media, irrigated adequately until they showed two pairs of true leaves. Afterward, they were transplanted to containers with the same growing media, but chemically fertilized. Seedlings were irrigated until sampling began. The experimental design was completely randomized under a 6 o 7 factorial, corresponding to six genotypes and seven evaluation sampling dates. The evaluations were carried out for seedlings under irrigation, water deficit, and rewatering. It was evaluated dry matter accumulation (DM), for their different fractions (root and above ground), and leaf area (LA) as the bases for the determination of the physiological indices: leaf area ratio (LAR), net assimilation rate (NAR) and relative growth ratio (RGR). It could be concluded that the hybrid HTR - 051 presented less sensibility to the water deficit, suggesting that it could be indicated as a promissory citrus rootstock for water deficit conditions.
\end{abstract}

Index terms: Coastal Table Lands, hybrids, Citrus spp., Poncirus trifoliata.

\section{INTRODUÇÃO}

A produção dos citros, desde sua implantação à colheita, é submetida a contínuos e variados estresses de natureza biótica e abiótica de diferentes intensidades, associados às condições climáticas e edáficas; nos casos de estresses hídricos, estes se relacionam principalmente à presença de água no solo em épocas e quantidades apropriadas (Cruz, 2003). Nas áreas cultivadas com citros, no Brasil, é comum ocorrer deficiência hídrica no solo, associada a elevados déficits de pressão de vapor, aumentando as limitações à expressão da produtividade potencial (Medina, 1999).

A citricultura nordestina encontra-se assentada, principalmente, no ecossistema de Tabuleiros Costeiros, onde as plantas cítricas desenvolvem um sistema radicular pouco profundo, tornando-as mais vulneráveis a déficits hídricos, comuns nos meses de novembro a março. Germoplasma contendo genótipos que possuam diversidade de respostas à deficiência hídrica, é de interesse em programas de melhoramento genético, sendo importante o conhecimento dos mecanismos relacionados a tais respostas diferenciais. Nesse sentido, características fisiológicas podem ser empregadas na seleção de genótipos tolerantes à seca. Vários parâmetros têm sido estudados para avaliar a resposta das espécies vegetais ao estresse hídrico, destacando-se o potencial hídrico foliar, potencial osmótico, condutância estomática, transpiração e a atividade fotossintética (Nogueira et al., 2001; Nepomuceno et al., 2003). Em algodoeiro, têm-se proposto caracteres como condutância estomática, transpiração e a atividade fotossintética para a seleção de genótipos com tolerância à seca (Lopez et al., 1993). No entanto, para porta-enxertos cítricos, Pereira et al. (2003) recomendam avaliar o crescimento do sistema radicular e da parte aérea com base no acúmulo de matéria seca e do incremento da área foliar.

Os estudos das relações hídricas nas plantas e das interações causadas pelo déficit hídrico temporário nos processos fisiológicos são de fundamental importância, uma vez que o déficit hídrico tem efeitos em diversos processos fisiológicos das plantas, muitos dos quais refletem mecanismos de adaptação. Pelo conhecimento da variação do consumo de água por uma cultura em suas diferentes fases de desenvolvimento, pode-se inferir sobre os aspectos fisiológicos envolvidos no processo, assim como sobre suas conseqüências.

\footnotetext{
${ }^{1}$ (Trabalho 159-2005). Recebido: 05-10-2005. Aceito para publicação: 12-09-2006.

${ }^{2}$ Eng $^{\circ}$ Agrônomo. DSc. Professor Adjunto. Centro de Ciências Agrárias e Ambientais da UFBA (AGRUFBA) - cppeixot@ufba.br

${ }^{3}$ Eng $^{\mathrm{a}}$ Agrônoma. Mestre em Ciências Agrárias/UFBA - ellainnep@ bol.com.br

${ }^{4}$ Eng$^{\circ}$ Agrônomo. DSc. Pesquisador da Embrapa Mandioca e Fruticultura Tropical. Cruz das Almas - BA, wsoares@cnpmf.embrapa.br, castro@cnpmf.embrapa.br, ledo@cnpmf.embrapa.br

${ }_{5}^{5}$ Acadêmico AGRUFBA e bolsista de Iniciação Científica (PIBIC-CNPq) - fabioagronomia@bol.com.br, jutair@bol.com.br
} 
Relativamente ao estudo dos efeitos ambientais sobre o crescimento das plantas, são encontrados na literatura vários conceitos e técnicas. Em muitos casos, a análise de crescimento, com base em índices fisiológicos, tem sido empregada como ferramenta valiosa em estudos sobre diferenças de ordem genética ou ambiental. Sua determinação obedece a um processo seqüencial, considerando, normalmente, a fitomassa e a dimensão do aparelho fotossintetizante, permitindo avaliar o crescimento da planta como um todo e a contribuição de seus diferentes órgãos no crescimento total (Peixoto, 1998; Brandelero, 2001; Benincasa, 2004).

Avaliando o crescimento de diversos porta-enxertos cítricos, submetidos ao estresse por alumínio em cultivo hidropônico, Pereira et al. (2003) verificaram que o crescimento da parte aérea, a relação de área foliar e de massa foliar diminuíram em todos os porta-enxertos em presença de alumínio, sendo que, no limoeiro 'Cravo', esse decréscimo foi mais acentuado, principalmente no sistema radicular, diminuindo o crescimento a partir de $23 \mu \mathrm{mol} \mathrm{L}^{-1}$ de $\mathrm{Al}$, sendo esse porta-enxerto o mais sensível em relação a todos os caracteres de crescimento considerados.

Nos estudos ecofisiológicos das plantas, não se pode prescindir da análise de crescimento, pois fatores ambientais, como luz, temperatura, concentração de $\mathrm{CO}_{2}$ e disponibilidade de água e nutrientes, próprios de cada local, afetam sensivelmente vários índices fisiológicos, a exemplo da razão de área foliar, da taxa assimilatória líquida e da taxa de crescimento relativa, dentre outros. Com base no estudo das interações desses parâmetros com cada fator ambiental, em particular o estado hídrico da planta, pode-se conhecer a eficiência do crescimento e a habilidade de adaptação às condições ambientais de uma dada espécie ou variedade (Reis \& Muller, 1979; Peixoto, 1998).

$\mathrm{Na}$ mensuração das alterações no crescimento vegetal, o acúmulo de matéria seca é o parâmetro mais significativo, uma vez que resulta da associação de vários outros componentes. Assim, objetivou-se, nesta pesquisa, determinar fatores responsáveis pela tolerância à seca e/ou capacidade de recuperação de diferentes genótipos de citros ao estresse hídrico, bem como identificar características de crescimento que expliquem sua capacidade de tolerância e/ou sensibilidade a esse estresse.

\section{MATERIAL E MÉTODOS}

O estudo foi conduzido na Embrapa Mandioca $\boldsymbol{e}$ Fruticultura Tropical, município de Cruz das Almas, Recôncavo Baiano, sob condições controladas de casa de vegetação. O material vegetal utilizado foi obtido no Banco Ativo de Germoplasma de Citros, compreendendo sementes dos híbridos tangerineira 'Sunki' [C. sunki (Hayata) hort. ex Tanaka) (TSK) õ citrange [C. sinensis (L.) Osbeck õ Poncirus trifoliata (L.) Raf.] 'Troyer' (CTTR): TSK x CTTR - 002 e TSK x CTTR - 017, além do híbrido trifoliado HTR 051, estes gerados pelo Programa de Melhoramento Genético de Citros da Embrapa Mandioca e Fruticultura Tropical. Utilizaramse também sementes dos limoeiros 'Cravo' $(C$. limonia Osbeck) (LCR) e 'Volkameriano' (C. volkameriana V. Ten. \& Pasq.) (LVK) e da laranjeira 'Azeda' (C. aurantium L.) (LAZ). As sementes tiveram seu tegumento externo (testa) removido de modo a facilitar a germinação, sendo plantadas em bandejas de isopor tipo colméia, preenchidas com uma mistura de substrato composto de Plantmax e fibra de coco, na proporção de 1:1.

Seedlings (pés-francos ou plantas oriundas de propagação por sementes) foram obtidos a partir de 300 sementes de cada genótipo. Sua emergência ocorreu de oito a dez dias após a semeadura, sendo os mesmos cultivados durante 120 dias até o período do desbaste e transplante para recipientes definitivos. Essa operação deu-se após a presença de dois pares de folhas permanentes, quando as plantas foram transferidas para recipientes com capacidade de $500 \mathrm{~mL}$ (11,0 cm de altura, diâmetro superior de
9,6 cm e inferior de 5,9 cm), contendo a mesma mistura usada na germinação das sementes, empregando-se, porém, adubação complementar com 150 g de $\operatorname{Osmocot}^{\circledR}(\mathrm{NPK})$ e de PageMix ${ }^{\circledast}($ micronutrientes) para cada $50 \mathrm{~kg}$ da mistura. As plantas foram irrigadas a cada dois dias até o início do experimento, quando apresentavam de três a quatro pares de folhas definitivas, ocasião em que foram iniciadas as avaliações da área foliar (AF), utilizandose de um integrador de área marca Delta T mod. MK2, e da matéria seca total (MS) da planta em suas diferentes frações (raiz e parte aérea), obtida após secagem em estufa a $75^{\circ} \mathrm{C}$ com ventilação de ar forçada, como base para determinação de diversos índices fisiológicos

Com a obtenção da AF e da MS, em intervalos regulares de tempo (T), tanto nas fases irrigadas como nas fases em déficit hídrico, foi possível determinar os índices fisiológicos descritos a seguir, com suas respectivas fórmulas matemáticas, de acordo com a recomendação de vários textos dedicados à análise quantitativa do crescimento (Reis \& Muller, 1979; Pereira \& Machado, 1987; Peixoto, 1998; Brandelero et al., 2002; Benincasa, 2004): taxa de crescimento relativo (TCR), que expressa o incremento na massa de matéria seca (MS), por unidade de massa inicial, em um intervalo de tempo ( $\mathrm{g} \mathrm{g}$ ${ }^{1}$ dia $\left.^{-1}\right)$, usando-se, para valores médios, a expressão TCR=Ln.MS ${ }_{2}-$ Ln.MS $1 / \mathrm{T}_{2}-\mathrm{T}_{1}$, onde Ln é o logaritmo neperiano e $\mathrm{T}$ o tempo; razão de área foliar (RAF), que representa a relação entre a área foliar e a massa seca $\left(\mathrm{dm}^{2} \mathrm{~g}^{-1}\right)$ da planta, onde $\mathrm{RAF}=\mathrm{AF} / \mathrm{MS}$; taxa assimilatória líquida (TAL), que representa a taxa de incremento de matéria seca (MS) por unidade de área foliar existente na planta, por unidade de tempo $\left(\mathrm{g} \mathrm{dm}^{-2} \mathrm{dia}^{-1}\right)$, obtida pela equação $\mathrm{TAL}=\left(\mathrm{MS}_{2}-\mathrm{MS}_{1}\right) \times\left(\mathrm{LnAF}_{2}-\right.$ $\left.\mathrm{LnAF}_{1}\right) /\left(\mathrm{AF}_{2}-\mathrm{AF}_{1}\right) \times\left(\mathrm{T}_{2}-\mathrm{T}_{1}\right)$

Foram realizadas duas avaliações com as plantas devidamente irrigadas, observando-se um intervalo de quatro dias. Em seguida, o déficit hídrico foi induzido por suspensão da irrigação durante 12 dias, período no qual se efetuaram mais três avaliações com intervalos de quatro dias, quando se iniciou o período de recuperação do estresse hídrico (aos 16 dias do início das avaliações). Na sequiência, procederam-se mais duas avaliações com intervalos de 24 horas (aos 17 e 18 dias do início das avaliações).

O delineamento experimental foi o inteiramente casualizado, com seis genótipos (variedades e híbridos) sob diferentes regimes hídricos: com irrigação (0 e 4 dias) e sem irrigação, considerando-se diversos períodos de exposição ao estresse (4; 8 e 12 dias), seguido de tempo de recuperação ( 1 e 2 dias), perfazendo um total de sete tempos de avaliação, com cinco repetições por tratamento. Foi realizada análise de variância considerando-se o modelo estatístico do delineamento inteiramente casualizado, no esquema fatorial 6 x 7 (seis genótipos e sete tempos de avaliação). Foi aplicado o teste de Tukey, a 5\% de probabilidade, para os fatores em estudo e para o desdobramento da interação em cada situação.

\section{RESULTADOS E DISCUSSÃO}

A produção de massa seca total pelos diferentes genótipos estudados mostrou-se sensível à aplicação dos tratamentos hídricos (Tabela 1). Embora o limoeiro 'Volkameriano' e a laranjeira 'Azeda' tenham apresentado, para esta variável, médias superiores às dos demais genótipos, não diferindo entre si, verificou-se que o LVK, no oitavo dia de déficit, já manifestava um decréscimo de $10 \%$ em sua MS e, aos 12 dias, de 14\%, diferindo significativamente do período irrigado, não havendo recuperação após o déficit hídrico. O limoeiro 'Cravo', por sua vez, apresentou decréscimo na MS de 14\%, aos 12 dias de déficit, e uma recuperação logo no primeiro dia de irrigação, de $22 \%$, voltando a incrementar sua produção de matéria seca. Os genótipos restantes (laranjeira 'Azeda' e híbridos HTR - 051, TSK x CTTR - 002 e TSK x CTTR - 017) não apresentaram diferenças significativas, indicando que não sofreram variações expressivas no tocante ao seu conteúdo de matéria seca em função dos déficits 
TABELA 1 - Médias ${ }^{1}$ da variável massa seca total (g) de porta-enxertos de citros avaliados sob irrigação, estresse hídrico e re-irrigação. Cruz das Almas - BA, 2004.

\begin{tabular}{|c|c|c|c|c|c|c|c|c|}
\hline \multirow{3}{*}{ Porta-enxerto } & \multicolumn{7}{|c|}{ Avaliações } & \multirow{3}{*}{ Médias } \\
\hline & \multicolumn{2}{|c|}{$\begin{array}{c}\begin{array}{c}\text { Irrigado } \\
\text { (dias) }\end{array} \\
\end{array}$} & \multicolumn{3}{|c|}{$\begin{array}{l}\text { Déficit hídrico } \\
\text { (dias) }\end{array}$} & \multicolumn{2}{|c|}{$\begin{array}{c}\text { Re-irrigado } \\
\text { (dias) }\end{array}$} & \\
\hline & $\mathbf{0}$ & 4 & 4 & 8 & 12 & 1 & 2 & \\
\hline LCR & $1,8 \mathrm{bB}$ & $2,1 \mathrm{bAB}$ & $2,4 \mathrm{bA}$ & $2,1 \mathrm{bAB}$ & $1,8 \mathrm{bB}$ & $2,2 \mathrm{bAB}$ & $2,2 \mathrm{bAB}$ & $2,1 \mathrm{~b}$ \\
\hline LVK & $2,3 \mathrm{aB}$ & $2,9 \mathrm{aA}$ & $2,9 \mathrm{aA}$ & $2,6 \mathrm{aAB}$ & $2,5 \mathrm{aB}$ & $2,6 \mathrm{aAB}$ & $2,4 \mathrm{abB}$ & $2,6 a$ \\
\hline LAZ & $2,4 \mathrm{aB}$ & $2,6 \mathrm{aAB}$ & $2,9 \mathrm{aA}$ & $2,8 \mathrm{aA}$ & $2,5 \mathrm{aAB}$ & $2,5 \mathrm{abAB}$ & $2,6 \mathrm{aAB}$ & $2,6 \mathrm{a}$ \\
\hline HTR - 051 & $0,8 \mathrm{cA}$ & $1,0 \mathrm{cA}$ & $0,9 \mathrm{eA}$ & $0,8 \mathrm{dA}$ & $0,9 \mathrm{cA}$ & $0,8 \mathrm{eA}$ & $0,9 \mathrm{dA}$ & $0,8 \mathrm{~d}$ \\
\hline TSK x CTTR - 002 & $1,7 \mathrm{bA}$ & $1,8 \mathrm{bA}$ & $1,9 \mathrm{cA}$ & $1,9 \mathrm{bA}$ & $1,7 \mathrm{bAB}$ & $1,7 \mathrm{cA}$ & $1,7 \mathrm{cA}$ & $1,7 \mathrm{~b}$ \\
\hline TSK x CTTR - 017 & $1,0 \mathrm{cA}$ & $1,1 \mathrm{cA}$ & $1,2 \mathrm{dA}$ & $1,2 \mathrm{cA}$ & $1,0 \mathrm{cA}$ & $1,3 \mathrm{dA}$ & $1,2 \mathrm{dA}$ & $1,3 \mathrm{c}$ \\
\hline Médias & $1,7 \mathrm{C}$ & $1,9 \mathrm{AB}$ & $2,0 \mathrm{~A}$ & $1,9 \mathrm{AB}$ & $1,7 \mathrm{C}$ & $1,9 \mathrm{ABC}$ & $1,9 \mathrm{BC}$ & \\
\hline
\end{tabular}

${ }^{1}$ Médias seguidas pela mesma letra minúscula nas colunas e maiúscula nas linhas não diferem estatisticamente entre si, pelo teste de Tukey, a $5 \%$ de probabilidade.

hídricos aplicados. Decréscimo da massa seca sob condições de déficit hídrico também foi observado por Paim (2002), em aroeira-dosertão (Myracrogruon urundeuva Fr. AII.).

Levando-se em consideração o caráter área foliar (Tabela 2), o limoeiro 'Volkameriano' e a laranjeira 'Azeda', embora tenham diferido significativamente entre si no período de déficit hídrico, aos 8 e 12 dias, mostraram-se sempre superiores aos demais genótipos, nos diferentes regimes hídricos aplicados, seguidos do limoeiro 'Cravo'. Os híbridos HTR - 051 e TSK x CTTR - 017, que também diferiram ente si, apresentaram os menores valores de área foliar. Estas diferenças dizem respeito a fatores genéticos, uma vez que os referidos híbridos, além de menor porte, possuem folhas menores e trifoliadas, em relação aos limoeiros 'Cravo' e 'Volkameriano' e à laranjeira 'Azeda', variedades utilizadas tradicionalmente como porta-enxerto.

Verificou-se, à exceção dos híbridos HTR - 051 e TSK x CTTR - 017, que os genótipos apresentaram decréscimos nas taxas de razão de área foliar (RAF) após o período de re-irrigação (Figura 1), provavelmente pela tendência de esta diminuir com o crescimento da planta, conforme observado por Peixoto (1998) e Brandelero (2001) em plantas de soja [Glycine Max (L.) Merrill], uma vez que, inicialmente, a maior parte do material fotossintetizado é convertida em folhas, visando à maior captação da radiação solar disponível. Os limoeiros 'Cravo' e 'Volkameriano', a laranjeira 'Azeda' e o híbrido TSK x CTTR - 002 apresentaram comportamentos semelhantes nos diferentes regimes hídricos, indicando diminuição a partir do início do período do estresse hídrico, havendo uma continuidade desses, mesmo no período re-irrigado, à exceção do limoeiro 'Cravo'. Os híbridos HTR - 051 e TSK x CTTR - 017 manifestaram uma tendência de estabilização do índice fisiológico RAF durante o período de estresse hídrico, indicando uma possível menor sensibilidade ao mesmo.

Os decréscimos encontrados nas taxas da razão de área foliar, entre os diferentes genótipos estudados, têm sustentação em observações de Benincasa (2004), afirmando a citada autora que esse comportamento está associado à redução da área foliar útil a partir de uma determinada fase, o que, neste estudo, ocorreu no período da re-irrigação, após 18 dias do início das avaliações, totalizando 138 dias da emergência das plântulas.

Os valores médios da taxa assimilatória líquida, nos diferentes regimes hídricos, são apresentados na Figura 2 e refletem a dimensão do sistema fotossintético que é envolvido na produção de matéria seca. Observa-se que, no período irrigado, todos os genótipos apresentaram valores médios positivos da TAL, isto, provavelmente, devido à turgescência foliar, permitindo a abertura estomática e favorecendo as trocas gasosas, com a entrada de $\mathrm{CO}_{2}$, de forma a atender à grande demanda de assimilados dos órgãos em crescimento, sendo que o limoeiro 'Volkameriano' e o híbrido HTR 051 apresentaram valores superiores aos demais, indicando a maior eficiência fotossintética dos mesmos.

Com a suspensão da irrigação, todos os genótipos decresceram suas taxas assimilatórias líquidas (TAL), apresentando valores negativos, à exceção do HTR - 051, que, mesmo em baixos níveis, manteve um balanço positivo nas taxas de fotossíntese/ respiração + fotorrespiração (já que é uma planta $\mathrm{C}_{3}$ ), refletindo-se na manutenção de seu crescimento.

A laranjeira 'Azeda' e os híbridos TSK õ CTTR - 002 e HTR - 051 apresentaram decréscimos na taxa assimilatória líquida, no período de déficit hídrico, de 181\%, 230\% e 97\%, respectivamente, com taxas de recuperação após a re-irrigação da ordem de $361 \%$,

TABELA 2 - Médias ${ }^{1}$ da variável área foliar $\left(\mathrm{dm}^{2}\right)$ de porta-enxertos de citros avaliados sob irrigação, estresse hídrico e re-irrigação. Cruz das Almas - BA, 2004

\begin{tabular}{|c|c|c|c|c|c|c|c|c|}
\hline \multirow{3}{*}{ Porta-enxerto } & \multicolumn{7}{|c|}{ Avaliações } & \multirow{3}{*}{ Médias } \\
\hline & \multicolumn{2}{|c|}{$\begin{array}{c}\text { Irrigado } \\
\text { (dias) }\end{array}$} & \multicolumn{3}{|c|}{$\begin{array}{c}\begin{array}{c}\text { Déficit hídrico } \\
\text { (dias) }\end{array} \\
\end{array}$} & \multicolumn{2}{|c|}{$\begin{array}{c}\text { Re-irrigado } \\
\text { (dias) }\end{array}$} & \\
\hline & $\mathbf{0}$ & 4 & 4 & 8 & 12 & 1 & 2 & \\
\hline LCR & $1,2 \mathrm{bA}$ & $1,2 \mathrm{bA}$ & $1,4 \mathrm{bA}$ & $1,3 \mathrm{bcA}$ & $1,2 \mathrm{cA}$ & $1,3 \mathrm{bA}$ & $1,4 \mathrm{aA}$ & $1,3 \mathrm{c}$ \\
\hline LVK & $1,5 \mathrm{aA}$ & $1,7 \mathrm{aA}$ & 1,6abA & $1,5 \mathrm{bA}$ & $1,6 \mathrm{bA}$ & $1,7 \mathrm{aA}$ & $1,6 \mathrm{aA}$ & $1,6 \mathrm{~b}$ \\
\hline LAZ & $1,6 \mathrm{aAB}$ & $1,8 \mathrm{aAB}$ & $1,7 \mathrm{aAB}$ & $1,8 \mathrm{aAB}$ & $1,9 \mathrm{aA}$ & $1,8 \mathrm{aAB}$ & $1,5 \mathrm{aB}$ & $1,7 \mathrm{a}$ \\
\hline HTR-051 & $0,4 \mathrm{dA}$ & $0,5 \mathrm{cA}$ & $0,3 \mathrm{eA}$ & $0,3 \mathrm{eA}$ & $0,3 \mathrm{eA}$ & $0,3 \mathrm{dA}$ & $0,4 \mathrm{cA}$ & $0,3 \mathrm{f}$ \\
\hline TSK x CTTR-002 & $1,1 \mathrm{bB}$ & $1,2 \mathrm{bA}$ & $1,0 \mathrm{cB}$ & $1,2 \mathrm{cA}$ & $1,0 \mathrm{cdB}$ & $1,0 \mathrm{cB}$ & $1,0 \mathrm{bB}$ & $1,0 \mathrm{~d}$ \\
\hline TSK x CTTR-017 & $0,7 \mathrm{cA}$ & $0,8 \mathrm{cA}$ & $0,7 \mathrm{dA}$ & $0,7 \mathrm{dA}$ & $0,7 \mathrm{dA}$ & $0,8 \mathrm{cA}$ & $0,8 \mathrm{bA}$ & $0,7 \mathrm{e}$ \\
\hline Médias & $1,1 \mathrm{~B}$ & $1,2 \mathrm{~A}$ & $1,1 \mathrm{AB}$ & $1,1 \mathrm{AB}$ & $1,1 \mathrm{AB}$ & $1,2 \mathrm{AB}$ & $1,1 \mathrm{AB}$ & \\
\hline
\end{tabular}

${ }^{1}$ Médias seguidas pela mesma letra minúscula nas colunas e maiúscula nas linhas não diferem estatisticamente entre si, pelo teste de Tukey, a 5\% de probabilidade. 


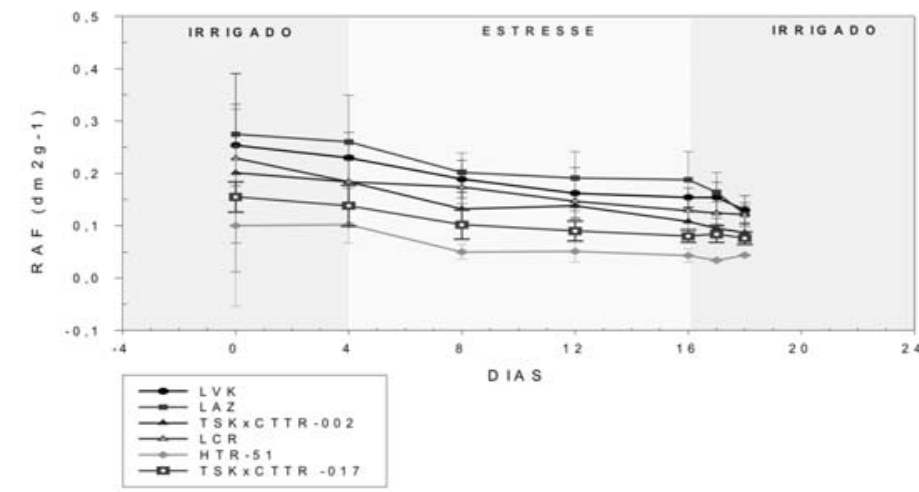

FIGURA 1 - Razão de área foliar (RAF) de genótipos de citros (LVK: limoeiro 'Volkameriano', LAZ: laranjeira 'Azeda', TSK: tangerineira 'Sunki', CTTR: citrange 'Troyer', LCR: limoeiro ‘Cravo', HTR: híbrido trifoliado) considerando diferentes regimes hídricos (irrigado: 0 e 4 dias; déficit hídrico com suspensão da hidratação: 8; 12 e 16 dias; e re-irrigação: 17 e 18 dias). Cruz das Almas - BA, 2004.

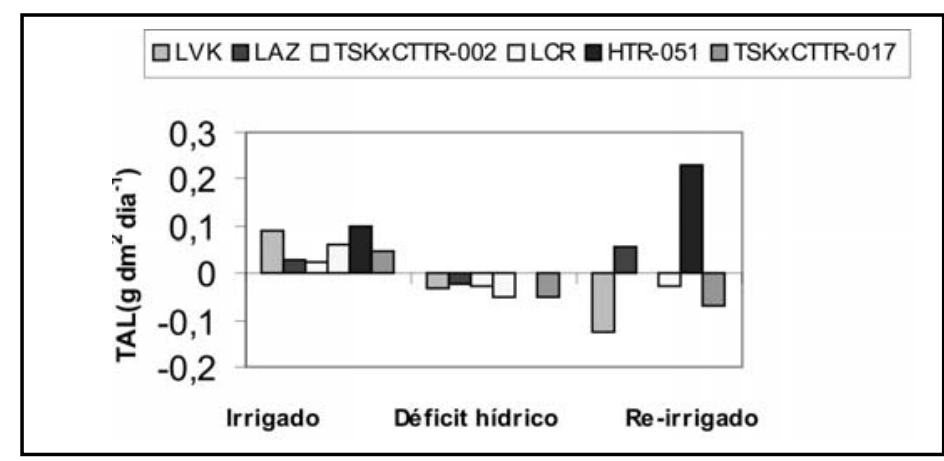

FIGURA 2 - Taxa assimilatória líquida (TAL) de genótipos de citros (LVK: limoeiro 'Volkameriano', LAZ: laranjeira 'Azeda', TSK: tangerineira 'Sunki', CTTR: citrange 'Troyer', LCR: limoeiro 'Cravo', HTR: híbrido trifoliado) considerando diferentes regimes hídricos (irrigado: $0 \mathrm{e}$ 4 dias; déficit hídrico com suspensão da hidratação: 8; 12 e 16 dias; e re-irrigação: 17 e 18 dias). Cruz das Almas - BA, 2004.

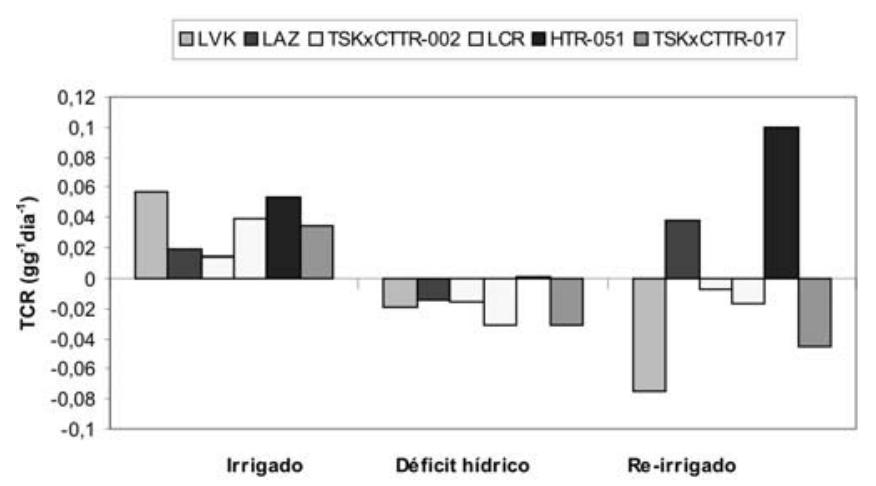

FIGURA 3 - Taxa de crescimento relativo (TCR) de genótipos de citros (LVK: limoeiro 'Volkameriano', LAZ: laranjeira 'Azeda', TSK: tangerineira 'Sunki', CTTR: citrange 'Troyer', LCR: limoeiro 'Cravo', HTR: híbrido trifoliado) considerando diferentes regimes hídricos (irrigado: 0 e 4 dias; déficit hídrico com suspensão da hidratação: 8; 12 e 16 dias; e re-irrigação: 17 e 18 dias). Cruz das Almas - BA, 2004.
$100 \%$ e $7.287 \%$, respectivamente, sendo que o HTR - 051 apresentou valores de TAL superiores aos do tratamento irrigado, o que demonstra sua menor sensibilidade ao déficit hídrico e o seu alto poder de recuperação da turgescência foliar, permitindo as trocas gasosas e, conseqüentemente, favorecendo o aumento da fotossíntese. Aumentos na TAL após a re-irrigação são interpretados como respostas do aparelho fotossintético a um aumento na demanda de assimilados pela planta.

Os resultados obtidos para a taxa de crescimento relativo (TCR) dos seis genótipos estudados podem ser visualizados na Figura 3. Verifica-se que todos os genótipos se relacionaram a valores positivos no período irrigado, declinando no período de déficit hídrico e apresentando taxas negativas, à exceção do híbrido HTR 051. Já no período de re-irrigação, somente a laranjeira 'Azeda' e o híbrido HTR - 051 manifestaram taxas positivas, indicando sua boa capacidade de recuperação quando re-irrigados.

No período irrigado, as TCR variaram de 0,014 a $0,057 \mathrm{~g} \mathrm{~g}^{-1}$ $\mathrm{dia}^{-1}$, sendo que o limoeiro 'Volkameriano' $\left(0,057 \mathrm{~g} \mathrm{~g}^{-1} \mathrm{dia}^{-1}\right)$ e o híbrido HTR - $051\left(0,054 \mathrm{~g} \mathrm{~g}^{-1} \mathrm{dia}^{-1}\right)$ foram os que apresentaram maiores valores para esse índice.

Os limoeiros 'Cravo' e 'Volkameriano', além do híbrido TSK x CTTR - 017, apresentaram os maiores decréscimos nas TCR (180\%, $133 \%$ e $190 \%$, respectivamente), seguidos do TSK x CTTR - 002 (214\%) em relação ao período irrigado, não sendo observada, inclusive, a recuperação destes após a re-irrigação. A laranjeira 'Azeda' e o híbrido HTR - 051 reduziram suas TCR, respectivamente, em $177 \%$ e $97 \%$, no período de déficit hídrico. Entretanto, exibiram grande poder de recuperação da turgescência foliar após a reirrigação, da ordem de $352 \%$ para a laranjeira 'Azeda' e de $8.230 \%$ para o híbrido HTR - 051, apresentando valores de TCR superiores aos do período irrigado $\left(0,037 \mathrm{~g} \mathrm{~g}^{-1} \mathrm{dia}^{-1}\right.$ e $0,099 \mathrm{~g} \mathrm{~g}^{-1} \mathrm{dia}^{-1}$, respectivamente).

Sendo a TCR uma estimativa da eficiência da planta em acumular matéria seca, pode-se inferir que o híbrido HTR - 051 foi o genótipo que apresentou maiores possibilidades de tolerar o déficit hídrico, bem como de retomar seu crescimento, já que a eficiência de produção por unidade de matéria seca durante o período de recuperação foi maior que aquela verificada no período irrigado, o que indica seu potencial de uso como porta-enxerto de citros em ambientes sujeitos a estiagem prolongada

\section{CONCLUSÕES}

1) Os índices fisiológicos RAF, TAL e TCR são ferramentas capazes de identificar a potencialidade de variedades de citros para a tolerância ao déficit hídrico.

2) A menor sensibilidade ao déficit hídrico apresentada pelo híbrido HTR - 051 qualifica-o como variedade a ser avaliada como porta-enxerto em combinação com diferentes copas cítricas comerciais em futuros estudos, sob condições de estresse hídrico.

3) Em razão do maior poder de recuperação, após o déficit hídrico, manifestado pelo híbrido HTR - 051 e pela laranjeira 'Azeda', tem-se que ambos são capazes de manter um balanço positivo da fotossíntese e da produção de matéria seca, em condições de veranicos temporários.

\section{REFERÊNCIAS}

BRANDELERO, E. M. Índices fisiológicos e rendimento de cultivares de soja no município de Cruz das Almas - Ba. 2001. 63f. Dissertação (Mestrado em Fitotecnia) - Escola de Agronomia, Universidade Federal da Bahia, Cruz das Almas, 2001.

BRANDELERO, E. M.; PEIXOTO. C. P.; SANTOS, J. M .B. S.; MORAES, J. C. C. M.; SILVA, V. Índices fisiológicos e rendimento de cultivares de soja no recôncavo bahiano. Magistra, Cruz das Almas, v. 14, n. 2, p. 77-88, 2002. 
BENINCASA, M.M.P. Análise de crescimento de plantas: noções básicas. Jaboticabal: FUNEP, 2004. 42p.

CRUZ, A. C. R. Consumo de água por cultura de citros cultivada em Latossolo Vermelho Amarelo. 2003. 78f. Tese (Doutorado em Agronomia) - Escola Superior de Agricultura "Luiz de Queiroz", Universidade de São Paulo, Piracicaba, 2003.

LOPEZ, J. M.; LEIDI, E. O.; LOPEZ, M.; GUTIERREZ, J. C. Fotossintesis, conductancia estomatica, eficiencia en el uso del agua e temperatura foliar de cultivares de algodon en respuesta al estres hidrico. Investigación Agraria: producción y protección vegetales, Madrid, v.8, n.1, p. 17-27, 1993.

MEDINA, C. L.; MACHADO, E. C.; GOMES, M. M. Condutância estomática, transpiração e fotossíntese em laranja 'Valência' sob deficiência hídrica. Revista Brasileira de Fisiologia Vegetal, Brasília, v.11, n.1, p.29-34, 1999.

NEPOMUCENO, L.; NEUMAIER, N.; FARIAS, J. R. B.; OYA, T. Tolerância à seca em plantas. Disponível em: <httr:// www.biotecnologia.com.Br/bio/bio23/2.htm.>. Acesso em: 07 mar..2003.

NOGUEIRA, R. J. M. C.; MORAES, J. A. P. V.; BURITY, H. A. Alterações na resistência à difusão de vapor das folhas e relações hídricas em aceroleiras submetidas a déficit de água. Revista Brasileira de Fisiologia Vegetal, Londrina, v.13, n.1, p.75-87, abr. 2001.
PAIM, A. C. B. Avaliação do efeito do estresse hídrico na estrutura, ecofisiologia e na bioquímica de plântulas de Myracrodruon urundeuva Fr.All. (ANACARDIACEAE). 2002. 80f. Dissertação - (Mestrado em Botânica), Universidade Estadual de Feira de Santana, Feira de Santana, 2002.

PEIXOTO, C. P. Análise de crescimento e rendimento de três cultivares de soja em três épocas de semeadura e três densidades de plantas. 1998. 151f. Tese - (Doutorado em Fitotecnia) - Escola Superior de Agricultura "Luiz de Queiroz", Universidade de São Paulo, Piracicaba, 1998.

PEREIRA, A. R.; MACHADO, E. C. Análise quantitativa do crescimento de vegetais. Campinas: Instituto Agronômico, 1987. 33p. (Boletim técnico, 114).

PEREIRA, W. E.; SIQUEIRA, D. L. de; PUIATTI, M. et al. Growth of citrus rootstocks under aluminium stress in hydroponics. Scientia Agricola, Piracicaba, v.60, n.1, p.31-41, jan./mar. 2003.

REIS, G. G.; MULLER, M. W. Análise de crescimento de plantas: mensuração do crescimento. Belém: CPATU, 1979. 35p. 